\title{
Vaginal Cylinder
}

National Cancer Institute

\section{Source}

National Cancer Institute. Vaginal Cylinder. NCI Thesaurus. Code C106079.

A metallic tube that is inserted into the vagina in order to facilitate delivery of vag inal intracavitary radiation therapy. 